\title{
Using mid-level cadres as substitutes for internationally mobile health professionals in Africa. A desk review Delanyo Dovlo*
}

\author{
Address: P.O Box CT5203, Cantonments, Accra, Ghana \\ Email: Delanyo Dovlo* - dovlod@yahoo.com \\ * Corresponding author
}

Published: 18 June 2004

Human Resources for Health 2004, 2:7 doi:10.1186/1478-449|-2-7
Received: II March 2004

Accepted: 18 June 2004

This article is available from: http://www.human-resources-health.com/content/2/1/7

(c) 2004 Dovlo; licensee BioMed Central Ltd. This is an Open Access article: verbatim copying and redistribution of this article are permitted in all media for any purpose, provided this notice is preserved along with the article's original URL.

\begin{abstract}
Background: Substitute health workers are cadres who take on some of the functions and roles normally reserved for internationally recognized health professionals such as doctors, pharmacists and nurses but who usually receive shorter pre-service training and possess lower qualifications.

Methods: A desk review is conducted on the education, regulation, scopes of practice, specialization, nomenclature, retention and cost-effectiveness of substitute health workers in terms of their utilization in countries such as Tanzania, Malawi, Mozambique, Zambia, Ghana etc., using curricula, evaluations and key-informant questionnaires.

Results: The cost-effectiveness of using substitutes and their relative retention within countries and in rural communities underlies their advantages to African health systems. Some studies comparing clinical officers and doctors show minimal differences in outcomes to patients. Specialized substitutes provide services in disciplines such as surgery, ophthalmology, orthopedics, radiology, dermatology, anesthesiology and dentistry, demonstrating a general bias of use for clinical services.

Conclusions: The findings raise interest in expanding the use of substitute cadres, as the demands of expanding access to services such as antiretroviral treatment requires substantial human resources capacity. Understanding the roles and conditions under which such cadres best function, and managing the skepticism and professional turf protection that restricts their potential, will assist in effective utilization of substitutes.
\end{abstract}

\section{Background}

The term "substitute health worker" (SHW) is used in this report to mean cadres of health workers who have taken on jobs, functions and roles that are normally the tasks of internationally recognized health professionals such as doctors, nurses and pharmacists. These "substitutes" usually receive shorter pre-service training than the original cadres and perform some or parts of the tasks normally carried out by the higher cadre. However, some observers say the term "substitute" is a misnomer, as these cadres fulfill clear and defined roles in health services. The term is thus used advisedly for alternative cadres that have been used in Africa for the traditional cadres that are recognized internationally.

There is renewed interest in such health cadres because of a crisis in human resources for health in Africa, due in part to increased migration of health professionals, the loss of health workers due to HIV/AIDS, the effect of countries' economic difficulties on health, and the expansion in 
services that tackling HIV/AIDS and other morbidities require. In poor countries that are unable to pay and retain internationally marketable health professionals, is it a feasible option to consider delegating critical skills and functions to less academically qualified practitioners? The nature of "substitutes" makes them very specific to a country and thus not involved in international health labor market dynamics.

Substitutes for doctors and other cadres have come about for a number of reasons, some of which are discussed below.

War and conflict situations in some countries resulted in high demand for surgical, orthopedic and obstetric skills in the absence of trained doctors. Eritrea and Mozambique are examples of this situation. Libombo and Usta (2001) recorded that Mozambique in 1984, after the war of independence, decided to initiate what is now known as the Surgical Technician program, after the emigration of some $85 \%$ of its doctors [1].

Economic and social crisis, including high population growth and rising health demands, meant many countries simply did not have enough doctors or professional nurses, and those available would not serve in the rural areas. Most of the other countries that use substitutes probably fall into this category.

Primary health care and other basic care concepts may have necessitated creation of new cadres to cater for nontraditional services as countries expanded rural health centers and tried to shift emphasis from hospitals. In Ghana, Akor et al. (1995) credit a policy decision to establish a "Rural Health Service" after independence with training of "health centre superintendents" cadres later known as medical assistants [2].

Arguably, several advantages can be found for using SHWs. The economic and health crises facing many parts of Africa makes this a very attractive way of securing health care at feasible costs. But there may also be disadvantages to using less-trained workers.

\section{A health sector crisis in Africa}

There is some evidence that health indicators improved in sub-Saharan Africa in the immediate post-colonial decades, but the past two decades have witnessed resurgence of the "old" communicable diseases such as tuberculosis and malaria and in addition, emergence of "new" epidemics of HIV/AIDS and noncommunicable diseases that have eroded these gains. Sanders et al. (2003) estimated that in 17 out of 48 countries in sub-Saharan Africa, life expectancy fell between 1981 and 1999. This "crisis" is further amplified by a human resources predicament caused by low motivation of health workers and a brain drain of trained professionals 3].

\section{Public service reforms and managing human resources for health}

Many African countries have undergone public service and health sector reforms since the $1990 \mathrm{~s}$. Reforms in Cameroon and Uganda, for example, required reductions in government expenditure on personnel. In some countries, many health workers were retrenched and employment freezes put in place. But the public sector continued to be the main provider of health services in the poorest countries despite this reduced workforce, which sometimes also lost staff to urban private (for-profit) services and to international migration $[4,5]$. Thus a constant challenge to providing equitable health services is the paucity of qualified health professionals, and as such, public-sector health services in tackling staffing issues need to consider types of cadres who are likely to stay in the country. Public and health sector reform documentation rarely mentioned use of substitutes, though policies place emphasis on primary health care.

\section{Substitution and skill mix}

The main health professions have influenced the way cadres were structured and used. For example, in Ghana, Malawi, Zambia, and Kenya, nurses' lobbies have succeeded in banning the training of "enrolled nurses" despite increased migration and shortages of registered nurses. The issue of what will constitute a "right" mix of professional and mid-level staff is a sensitive one. Using "substitutes" in staff mixes can have positive implications for the cost of service delivery, although health services have generally limited the numbers of substitutes produced. In Ghana, Ministry of Health data show that two medical schools produce about 200 doctors a year, whilst the single school for medical assistants produces an average of only 30 medical assistants a year.

Skill mix also relates to the scope of practice allowed for the substitutes and the regulatory bodies; professional associations in some countries appear to have restricted significantly what such cadres can do. Severely limiting scopes of practice may reduce the strategic effectiveness of substitutes and their ability to meet health needs in rural areas. Buchan and Dal Poz (2002) proposed that skill mixes be determined in terms of the following $[6]$ :

\section{Skill shortages}

\section{Cost containment}

\section{Quality improvement}

4. New technology or new health interventions 
5. New health programs requiring certain types of skills.

The information on substitution in Africa suggests that addressing skill shortages and cost-containment is the main reason for following this strategy in Africa.

\section{Methods}

This review has the following objectives:

To identify and describe experiences with substitution of skills in the health care workforce in African countries and to assess whether these experiences have been evaluated and what the results of these evaluations were

A desk review was conducted on WHO documentation, reports and other resources from various countries and Internet searches for relevant information. Costs did not allow for country visits and more detailed studies. Publications on the use of such cadres in Africa were difficult to find, and papers on other subjects that partially documented experiences of substitute health workers (SHW) were used in the absence of comprehensive evaluations.

Further information was sought from ministries of health (permanent secretaries, human resources directors, regulatory councils) and WHO representatives in a number of countries known to have substitute health workers (Zambia, Tanzania, Uganda, Mozambique, Eritrea, Zimbabwe, Nigeria, etc.) using faxes and emails. Requests for information were also sent to two health-related listservs HIF-net and AFRO-Nets. "Google" Internet searches were conducted using a variety of search words including strings of "medical assistants", "clinical officer", "assistant medical officer", qualified with "Africa" or "sub-Saharan Africa". Responses to the request messages were scattered and slow; often there were no responses. In addition, a short questionnaire was sent to key informants who appeared to have had experience with such cadres, in order to elicit their opinions.

This paper is a distillation of various pieces of information and data derived from collating and analyzing experiences expressed in a variety of sources, including curriculums of training schools as well as personal communication from key informants conversant with the development and training of substitute cadres.

The use of substitute health workers is quite common in Africa, but reviews and evaluations, where done, are not published. A lot of literature existed on "substitution" in the developed world, especially in the United States, where professional groups for physician assistants, medical assistants, nurse anesthetists and nurse practitioners existed. Websites of faith-based health service providers indicated that they clearly made significant use of substi- tution in Africa and made reference to this practice in documenting their activities.

The information collated was analyzed in terms of the education, regulation, scopes of practice and specialization of such workers. Evidence was also sought on their motivation, career pathways and the cost-effectiveness and advantages and disadvantages of using such cadres.

\section{Results and discussion \\ Concept and definition of substitution in Africa}

No specific definition of "substitute health worker" was found in the literature, and indeed the term was rarely used. "Skill delegation to mid-level health workers" and "skills substitution" were sometimes used. For the operational purposes in this review, substitute health workers were described simply as

"health cadres who have been trained for shorter periods and required lower entry educational qualifications, to whom are delegated functions and tasks normally performed by more established health professionals with higher qualifications".

This paper concentrates mainly on physician's substitutes, but where necessary it illustrates concepts with reference to substitutes for nurses and pharmacists.

Four main forms of substitution in Africa are identified and categorized in this study.

Indirect substitution/task delegation, i.e. substitution using an existing but different profession

An example of this occurs when tasks carried out by physicians are taken up by nurses. Several examples of this type of substitution were found. In Ghana, the "Life Saving Skills Training Project" trained midwives in rural areas to carry out delivery-related tasks normally undertaken by doctors. South Africa (Choice on Termination of Pregnancy (CTOP) Act 1996) and Zambia have changed their abortion laws and given new roles to nurses and midwives, including tasks normally restricted to physicians [7]. White et al. (1987) report that in the Congo in the 1950s, nurses were trained to perform surgery [8] and in Malawi, Ghana, Tanzania and Zambia, nurse anesthetists provided anesthesia for surgical operations. These skill substitutions also enhance the roles of these existing cadres and so are "indirect" forms of substitution.

However, anecdotal evidence suggests that significant informal substitution often occurred; nurses and other mid-level health workers in rural areas performed procedures normally disallowed by the regulations. Nurses in rural areas in Ghana, for example, delivered breech presentations and performed episiotomies, even without 
additional training and despite restrictions that these tasks be performed by physicians or under physician supervision.

Direct substitution: i.e. substituting an existing profession with new and different cadres

Many African countries have created country-specific cadres to carry out tasks that are internationally recognized as those of other professionals. This is a common form of substitution in Africa, where in most countries these substitutes are no longer "new", having been in place for over two decades. Examples include substitution for doctors using "clinical officers", "medical assistants", "assistant medical officers" and "surgical or obstetric technicians". Two further subtypes are identified.

- Partial substitutes, who carry out only limited and circumscribed tasks of doctors and refer other tasks to doctors. Medical assistants in Ghana and clinical officers in Zambia are examples of such substitutes.

- True or full substitutes, who carry out significant segments of the scope of practice of doctors. Assistant medical officers in Tanzania and surgical/obstetric technicians (tecnicos de cirurgýa) in Mozambique independently perform surgery and are examples of this type of substitution [9].

Intra-cadre skills delegation, i.e. delegating some specific, special tasks to less-trained cadres from the same profession

Tasks normally carried out by specialists are delegated to general practitioners with or without additional training. The West Africa Post-Graduate Medical College determined a gap in certain specialties in the region - psychiatry, ophthalmology, otorhinolaryngology and anesthesia - and had provided 18-month practical diploma courses for general practice physicians to undertake enhanced roles in these specialties. General practice nurses have been used as operating room nurses without the appropriate qualification.

Task delegation, i.e. delegation of some non-technical tasks to relieve professionals of unwarranted workload

Clerical tasks in wards, such as administration of patient reports, can be delegated to ward clerks working closely with nurses. The health sector in Ghana recently authorized the creation of "health aides" aimed at relieving professional nurses of the more menial tasks on wards, such as lifting or bed-bathing patients,

A basic underlying factor in all substitutions is that the worker to whom the tasks are delegated is not trained to the same level or qualification as the cadre who normally carries out these tasks. Laws or regulations should normally formalize substitution, but it is also recognized that substantial informal skill delegation exists because of unfilled needs in rural and remote areas. Perhaps most vivid is the story of an illiterate Ethiopian woman trained to repair vesico-vaginal fistulae whilst working with an Australian missionary doctor. Morrow and Kidane (2000) also report on the training of mothers to give chloroquine anti-malaria treatment at home in Ethiopia [10]. Table 1 summarizes the types of substitution that were determined from this review.

\section{Nomenclature of substitution}

Titles such "clinical officer" and "medical assistant" were commonly used in most countries, but appeared to mean different things in different countries. In Tanzania, clinical officers were the starting cadre, but this was the name of the enhanced substitutes in Kenya and Malawi. Table 2 provides a guide to the naming of doctors' substitutes at various levels of operation in various countries.

\section{Experiences with substitution in Africa \\ Production of substitute cadres}

The training of substitute cadres varies between countries in terms of entry qualifications, training duration and content of training. According to key informants, Mozambique had three levels of doctor substitutes, described as basic and middle-level "health technicians", and a "specialist" level. For the basic level, the requirement was a 10th-grade high school certificate for a pre-service training of 30 months. The cadres must work for two years before becoming eligible to be selected for a further 18-month course to become specialized.

CEDHA indicated that Tanzania provides a multi-step system, starting with the "clinical officer" (entry with grade 12) and ending at the assistant medical officer (AMO) specialist level. Kenyan Medical Training Center's clinical officers are trained for three years and registered after a year's "internship". A further 18 to 24 months' training confers a "higher diploma" and specialist grade in specific subjects such as anesthesia, ophthalmology and cataract surgery, reproductive health (with caesarean skills), and orthopedics.

Malawi's College of Health Sciences (MCHS) graduates clinical officers with certificates in "clinical medicine" after three years' training. Another year of training leads to postbasic qualifications in "clinical medicine" and "ophthalmology" as well as other specialties. MCHS also has a three-year diploma in pharmacy technology and with similar postbasic qualifications for pharmacist substitutes.

In the countries studied, the ministries of health were directly responsible for training institutions and not tertiary educational institutions. Tables 3,4 and 5 provide a 
Table I: Summary: types of substitution

\begin{tabular}{|c|c|c|}
\hline Substitution type & Brief description & Examples \\
\hline $\begin{array}{l}\text { I. Indirect substitution: Delegation of some } \\
\text { Professional Tasks }\end{array}$ & $\begin{array}{l}\text { Substituting a professional with an existing but } \\
\text { different professional (changes scope of } \\
\text { practice of another cadre to cope with } \\
\text { delegated tasks) }\end{array}$ & $\begin{array}{l}\text { I. Enhanced midwives' roles in Ghana } \\
\text { 2. Nurse anesthetists } \\
\text { 3. Enhanced abortion management roles for } \\
\text { nurses in Zambia and South Africa }\end{array}$ \\
\hline $\begin{array}{l}\text { 2. Direct substitution: Delegation of most } \\
\text { professional skills }\end{array}$ & $\begin{array}{l}\text { Substituting an existing profession with a newly } \\
\text { created cadre (both cadres may coexist, with } \\
\text { overlapping professional functions) }\end{array}$ & $\begin{array}{l}\text { I. Clinical officers/ medical assistants in Malawi } \\
\text { and Ghana } \\
\text { 2. Assistant medical officers and surgical } \\
\text { technicians in Tanzania and Mozambique }\end{array}$ \\
\hline $\begin{array}{l}\text { 3. Intra-cadre skills assignment or } \\
\text { delegation }\end{array}$ & $\begin{array}{l}\text { Delegating some specific "specialist" tasks to } \\
\text { professionals with less training, in the same } \\
\text { profession }\end{array}$ & $\begin{array}{l}\text { I. Diploma ophthalmologists, psychiatrists, } \\
\text { ENT specialists, WAHC } \\
\text { 2. Theatre and intensive care nurses without } \\
\text { formal training, in Ghana }\end{array}$ \\
\hline 4. Delegation of non-professional tasks & $\begin{array}{l}\text { Delegating certain aspects of tasks in order to } \\
\text { relieve professionals of unwarranted workload }\end{array}$ & $\begin{array}{l}\text { I. Health aides in Ghana. } \\
\text { 2. Pharmacy assistants in Ghana }\end{array}$ \\
\hline 5. Informal substitution. & $\begin{array}{l}\text { Existing "lower-trained" cadres, especially in } \\
\text { remote and rural areas, will carry out tasks in } \\
\text { the absence of the appropriately recognized } \\
\text { professional }\end{array}$ & Happens in many rural areas in Africa \\
\hline
\end{tabular}

Table 2: Names used for "doctor substitutes"

\begin{tabular}{|c|c|c|c|c|c|}
\hline Stages & Ghana & Malawi & Tanzania & Kenya & Mozambique \\
\hline Basic level & $\begin{array}{l}\text { Registered nurse } \\
\text { (nursing is required } \\
\text { for medical assistants } \\
\text { in Ghana) }\end{array}$ & Medical assistant & $\begin{array}{l}\text { Clinical officer } \\
\text { (medical assistants are } \\
\text { a step lower than } \\
\text { clinical officers) }\end{array}$ & Clinical officer & $\begin{array}{l}\text { Basic health "agent" } \\
\text { (general medicine, } \\
\text { pharmacy, dental) }\end{array}$ \\
\hline Postbasic level & Medical assistant & Clinical officer & $\begin{array}{l}\text { Assistant medical } \\
\text { officer }\end{array}$ & $\begin{array}{l}\text { Clinical officer (partly } \\
\text { specialized) e.g. skin, } \\
\text { ENT, anesthesia, } \\
\text { orthopedics, etc. }\end{array}$ & $\begin{array}{l}\text { Medium-level } \\
\text { technicians (general } \\
\text { medicine, pharmacy, } \\
\text { dental, preventive } \\
\text { medicine) }\end{array}$ \\
\hline Specialized & $\mathrm{n} / \mathrm{a}$ & $\begin{array}{l}\text { Clinical officer: } \\
\text { orthopedic, clinical } \\
\text { medicine, dental, etc. }\end{array}$ & $\begin{array}{l}\text { Assistant medical } \\
\text { officer-specialist } \\
\text { orthopedic, radiology, } \\
\text { surgery, dermatology, } \\
\text { anesthesia, etc. }\end{array}$ & & $\begin{array}{l}\text { Medical \& surgical } \\
\text { technicians } \\
\text { (specialists) }\end{array}$ \\
\hline
\end{tabular}

summary of training and staff production information from countries that responded to a questionnaire. If all the stages are taken together, the duration of education may be the same as for training a doctor, or nearly so.

\section{Scopes of practice/functions}

Scopes of practice of substitute cadres varied with each country, especially at the "specialized" cadre level found in Tanzania, Malawi and Mozambique, where "surgical technicians" are given a more extensive scope of practice. But some curricula reviewed show that most basic-level substitutes perform tasks limited to consultation, writing prescriptions and basic treatment and undertaking rela- tively minor procedures such as draining skin abscesses, suturing non-penetrating wounds and using plaster of Paris for fractures [11,12]. In Tanzania upgrading the basic (clinical officer) to "assistant medical officer" widens the scope of practice considerably; these cadres perform tasks such as emergency obstetric surgery and general surgery. Mtonga and Ndhovlu (2001) say Zambia purposely increased the scope of practice of nurses and midwives in the Nurses Act of 1997 to provide for a greater set of tasks to be carried out. Nurses and midwives can now do detailed physical examinations, insertion and removal of intrauterine devices, resuscitation including 
Table 3: Educational structure for "doctor substitutes"

\begin{tabular}{|c|c|c|c|c|c|}
\hline Country & Cadre name & Basic schooling & $\begin{array}{c}\text { Basic pre-service } \\
\text { education }\end{array}$ & $\begin{array}{l}\text { Postbasic } \\
\text { education }\end{array}$ & $\begin{array}{l}\text { Specialized } \\
\text { education }\end{array}$ \\
\hline \multirow[t]{3}{*}{ Ghana } & Medical assistant & 12 years & 3 years (nursing) & I year & none \\
\hline & Nurse anesthetist & 12 years & 3 years nursing & 18 months & none \\
\hline & Doctor & 12 years & 6 years & & $2-5$ years \\
\hline \multirow[t]{2}{*}{ Kenya } & Clinical officer & 12 years & $\begin{array}{l}3 \text { years (clinical } \\
\text { officer) }\end{array}$ & $\mathrm{I}-1.5 \mathrm{yrs}$ & \\
\hline & Doctor & 12 years & 6 years (medical school) & & $3-4$ years \\
\hline \multirow[t]{2}{*}{ Tanzania } & Clinical officer & 12 years & 2 years & $\begin{array}{l}3 \text { years }(\mathrm{AMO})(+5 \\
\text { years' practice) }\end{array}$ & 2 yr (AMOs) \\
\hline & Doctor & 12 years & 6 years (medical school) & & $3-4$ years \\
\hline \multirow[t]{2}{*}{$\begin{array}{l}\text { Mozambique basic, } \\
\text { medium \& specialist }\end{array}$} & $\begin{array}{l}\text { Medical assistant; } \\
\text { surgical/obstetrical } \\
\text { technician }\end{array}$ & 10 years & $\begin{array}{l}2.5 \text { years medical } \\
\text { assistant }\end{array}$ & $\begin{array}{l}\text { I.5 years - surgical/ } \\
\text { obstetrical technician }\end{array}$ & \\
\hline & Doctor & 12 years & $\begin{array}{l}6 \text { years (medical } \\
\text { school) }\end{array}$ & & \\
\hline \multirow[t]{3}{*}{ Malawi } & $\begin{array}{l}\text { Medical assistant/ } \\
\text { clinical officer }\end{array}$ & 12 years & $\begin{array}{l}3 \text { years (medical } \\
\text { assistant) }\end{array}$ & $\begin{array}{l}\text { I.5 years? (surgery) } \\
\text { clinical officer }\end{array}$ & \\
\hline & Pharmacy technologist & 12 & 3 years & I year & \\
\hline & Doctor & 12 years & 6 years (medical school) & & \\
\hline \multirow[t]{2}{*}{ Zambia } & Clinical officer & 12 yrs (O level) & 3 years & licentiates 18 months & $\begin{array}{l}2 \text { year "clinical officer } \\
\text { anesthetist" }\end{array}$ \\
\hline & Doctor & 12 years & 6 years (medical school) & & \\
\hline
\end{tabular}

Table 4: Estimated production: physicians and substitutes in selected countries

\begin{tabular}{lccc}
\hline & \multicolumn{2}{c}{ Average annual output } \\
\hline Country & $\begin{array}{l}\text { Clinical officer/Medical } \\
\text { assistants }\end{array}$ & $\begin{array}{l}\text { Assistant medical officer } \\
\text { (Postbasic) }\end{array}$ & Doctors \\
\hline Ghana & 30 & 0 & 200 \\
Tanzania & 300 & 40 & 50 \\
Kenya & 300 & 30 & 200 \\
Malawi & 100 & N/A & 20 \\
Mozambique & 300 & 20 (CO Anesthetist) & $20-25$ \\
Zambia & & & \\
\hline
\end{tabular}

intubations, vacuum delivery/extraction and performing manual vacuum aspiration (MVA) on post-abortion patients [7].

In Ghana, the role of health center superintendents (later to be known as medical assistants) in rural health services was described by Akor et al. (1995) in an MOH report succinctly as "Simple in its operation, Extensive in its scope, Economic in its cost, Efficient in its quality". But their curriculum did not permit the procedures the 1997 Zambian law allowed nurses and midwives to perform. Limiting the scope has implications for how useful such cadres can be in areas where quick referrals are not possible. Bergstrom (1998) proposes that certain types of services are crucial for patients at the first point of contact and suggests basic emergency obstetric functions at "first referral level", as follows [13].

- Surgery for caesarean section and symphysiotomy

-, Medical treatment for shock, eclampsia and sepsis

- Blood replacement facilities

- Manual and assessment functions (vacuum extraction, manual removal of placenta and application of partogram) 
Table 5: Estimates of physician and "substitute" stocks - selected countries

\begin{tabular}{llll}
\hline & Current available estimates of practicing cadres \\
\hline Country & $\begin{array}{l}\text { Clinical officer/Medical } \\
\text { assistants }\end{array}$ & $\begin{array}{l}\text { Assistant medical officer } \\
\text { (postbasic) }\end{array}$ & Doctors \\
\hline Ghana & $442 @$ & 0 & $* 1600$ \\
Tanzania & Not available & Not available & Not available \\
Kenya & $4300 \#(2300$ in public sector) & N/A & $* 4900$ (I200 in public sector) \\
Malawi & $442 \#$ & 301 (postbasic) & 315 \\
Mozambique & 627 (basic cadre)@ & 0 & $278 @$ \\
Central African Rep. & 182 & 121 & 671 \\
Uganda (I99I) & 750 & 40 (CO anesthetists) & 900 (approx) \\
Zambia & 1458 & &
\end{tabular}

\# Includes both "basic" and "postbasic" cadre types; @ public sector figures only. Data on this table are from: Zambia: WHO Representative's Office; Ghana Health Service HRD Database Kenya Medical Training Centre, Nairobi; Mozambique: CIHI Country Health Profile Series. Country Health Profile- 1995. Center for International Health Information. I60I N. Kent Street, Suite 1014. Arlington, VA 22209.; Uganda: CIHI Country Health Profile Series. Country Health Profile-1995.

Table 6: Regulation systems

\begin{tabular}{lllll}
\hline $\begin{array}{l}\text { Specific regulatory } \\
\text { body for clinical officers }\end{array}$ & $\begin{array}{l}\text { Board regulating } \\
\text { training systems }\end{array}$ & $\begin{array}{l}\text { MOH administrative } \\
\text { control only }\end{array}$ & $\begin{array}{l}\text { Umbrella board for } \\
\text { "allied health } \\
\text { professionals" }\end{array}$ & $\begin{array}{l}\text { "Medical Council" } \\
\text { registration }\end{array}$ \\
\hline Kenya & $\begin{array}{l}\text { Tanzania } \\
\text { Zambia }\end{array}$ & $\begin{array}{l}\text { Ghana } \\
\text { Malawi } \\
\text { Tanzania } \\
\text { Mozambique }\end{array}$ & $\begin{array}{l}\text { Namibia } \\
\text { South Africa }\end{array}$ & Zambia \\
& & & &
\end{tabular}

- Family planning functions

- Management of women at particular risk

- Neonatal special care.

If clinical officers are unable to provide these services, they may simply become a transit referral point, another bottleneck in emergency care. Specialization of doctor-substitute cadres in Tanzania is in seven disciplines (general medicine and surgery, ophthalmology, radiology, dermatology, anesthesiology and dentistry). Kenya trains for the disciplines of pediatrics, orthopedics, ENT/audiology, ophthalmology and reproductive health (caesarean section). Eye surgery is targeted mainly at cataract surgery, a major morbidity in the country. A new curriculum has been proposed to train clinical officers in anesthesia and "lung and skin diseases" (TB and leprosy care).

Lyttle (1998) described Malawi's specialized "orthopedic clinical officers" trained to perform tasks including: "managing common fractures, competent in closed reduc- tions, castings, application of lower limb traction and prescription of orthotics such as simple caliper braces. Capable of carrying out tendon releases for post-polio contractures, incision and drainage of abscesses such as pyomyositis and the debridement of open wounds" [14]. These examples of substitution are biased to clinical tasks rather than preventive services, but this probably reflects communities' health needs. Only Mozambique mentions similar cadres with specific preventive roles.

\section{Motivation: incentives and career pathways}

An anticipated advantage of using substitutes is that they cost less to remunerate and motivate. There was little information found on the incentives and motivating factors for such cadres, although some anecdotal references were made about "intrinsic" motivation arising from the job enhancement and enrichment their status offers, which enhanced their status in communities. Pay levels were low and were unlikely to be key motivators. Tanzanian medical substitutes could rise to assistant medical officer and specialist status; those with certain qualifications may enter a medical school and graduate as doctors. 
This unique "stepladder" career progression may also be a motivator. However, other views suggest that assistant medical officers did not attract recognition and respect from doctors and health administrators in Tanzania, despite doing work similar to a doctor's.

\section{Retention and international migration}

Retention against international migration is an attraction that the use of substitutes offers African countries. Retention in rural health services and other deprived areas is the other purported advantage. Voluntary surgical contraception (VSC) programs in Tanzania saw a very high attrition rate of physicians trained for VSC, which severely limited service provision until they started training clinical officers who were much less likely to leave [15]. In Kenya, the good retention of clinical officers resulted in a decision to extend their coverage to posts below the health center in peripheral "dispensaries". However, in Ghana a nursing qualification is required for medical assistant training, and some medical assistants have used their nursing certificates to emigrate.

Rural-urban distribution was not observed to be a particular problem with clinical officers and medical assistants. Key-informant reports from Kenya show that significant numbers worked in urban slum areas with few physicians. In Tanzania and Mozambique, some key-informant data (Ndeki, CEDHA) estimated that some $75 \%$ of clinical officers and assistant medical officers served in rural areas.

\section{Regulation and legal frameworks}

The review did not find much on the legal basis of substitute health workers in the literature. Regulatory bodies such as medical and nursing councils are suspected of protecting the interests of their professions by resisting the delegation of skills and limiting scopes of practice for substitute cadres. Only Kenya, among the countries for which information was available, had a specific professional board for clinical officers. This board regulated both their training and practice under an act of parliament. Tanzania (Tanganyika Medical Training Board) and Zambia have boards that regulate training institutions and methods but do not register and control practitioners. Medical assistants trained in Ghana are certified by the Ministry of Health but are not formally regulated under any specific ordinance. Table 6 described the various forms of regulation of substitute health workers.

\section{Comparisons of quality of care}

Few detailed papers were encountered that compared quality indicators between professionals and substitutes. Several positive comparisons of quality were reported without substantive data. None of the information reviewed indicated clearly negative results from the practice by substitutes. Some key informants, however, expressed reservations about the lack of support and supervision for the cadres. It is also possible that where professional regulation did not exist, as discussed in the previous section, this may affect the quality of care given by clinical officers. However, it is recognized that poor supervision and regulation can be a problem with any health cadre (doctors and nurses included) and can create quality of care problems. Shutt et al. (1994) found in Tanzania and Ghana that medical and nursing graduates were not able to deliver quality family practice services, as a result of curriculum design and training methods [15]. Inambao (2001), in a study on rationalization of cadres in Tanzania, similarly suggests that problems with quality of training are translated into quality of practice problems for medical assistants. Ofori-Adjei and Arhinful (1998) also studied medical assistants in Ghana and showed that they persisted in unconventional treatment patterns after in-service training, despite having the correct knowledge. And even knowledge deteriorated after a year, with instances of under- and/or overprescribing of chloroquine for malaria, buttressing the need for continuous reinforcement of training with support and supervision [16].

In one of the few assessments comparing medical assistants with doctors, Lin and Franco (2000), assessed quality of child care in Malawi and showed a lack of significant difference between doctors and medical assistants. Only $20 \%$ of doctors and $22 \%$ of medical assistants were observed to use "adequate diagnostic process" when examining an under-five child [17]. Vaz et al. (1999) in a detailed assessment of over 10,000 interventions by "surgical technicians", showed that the quality was effectively identical to interventions by doctors in terms of complication rates. Mortality rates recorded were of $0.4 \%$ (emergency surgery) and $0.1 \%$ (elective surgery); 377 of 10,258 cases had complications, with 37 fatalities [9].

\section{Inter-cadre relations (between substitutes and the substituted)}

Bergstrom (1998) said that delegation of responsibility in Mozambique had implied abolishing conventional professional boundaries of doctors. However, initial hostility changed to fruitful collaboration and to mutual recognition of new professional turfs [13]. Influential obstetrician-gynecologist leadership in Ghana was noted to have been important in gaining acceptance for an enhanced role for midwives in post-abortion care [18]. Concerns by professional groups about potential loss of earnings are dissipated by the benefits of reduced workloads and increased time for higher professional demands. With nursing, however, as mentioned previously, professional councils and associations helped to reverse the use of enrolled nurses. 
Table 7: Cost determinants - doctors and doctor substitutes

\begin{tabular}{|c|c|}
\hline Doctors & Clinical officers/Medical assistant, etc. \\
\hline $\begin{array}{l}\text { 1. Require longer pre-professional education } \\
\text { 2. Professional training is significantly long } \\
\text { 3. Training requires expensive and highly qualified tutors } \\
\text { 4. The training is in tertiary facilities with sophisticated equipment and } \\
\text { diagnostic facilities } \\
\text { 5. The training tries to meet "International standards", which may mean } \\
\text { non-relevant courses } \\
\text { 6. Their salaries are higher; they are difficult to retain in rural areas and } \\
\text { are more likely to migrate due to international complementary } \\
\text { recognition } \\
\text { 7. Often require expensive technical backup and support (laboratories, } \\
\text { etc.) } \\
\text { 8. Patient outcomes better? (Fewer repeat visits?) }\end{array}$ & $\begin{array}{l}\text { I. Need shorter basic or pre-professional education } \\
\text { 2. Require shorter professional training } \\
\text { 3. Requires smaller numbers of highly trained tutors and professionals } \\
\text { 4. Can be trained in secondary and primary care facilities } \\
\text { 5. Training can focus on specific immediate and relevant needs } \\
\text { 6. Salaries after employment are considerably lower whilst being } \\
\text { retained in rural areas. Unlikely to emigrate: skills not marketable } \\
\text { internationally } \\
\text { 7. Use of fewer expensive diagnostic tests and equipment in their } \\
\text { practice } \\
\text { 8. Cost of outcomes/complications to clients may be a problem }\end{array}$ \\
\hline
\end{tabular}

\section{Substitute health workers in private practice roles}

Information from the available evidence is that substitute health cadres were found largely in the public sector and related faith-based mission services. Increasingly, however, clinical officers are beginning to find their way into private-sector services. Clinical officers in Kenya initially were allowed to practice in the private sector only after 10 years' experience in the public sector. This period was reduced to three years as structural-adjustment policies restricted the public sector's ability to employ staff. A recently-won right by government doctors in Malawi to private practice is thought to have caused an urban drift, but it was not clear if the privilege extended to clinical officers [19].

\section{Comparing costs}

The costs of training health workers will vary widely between countries. Again, very little hard data were found that analyzed the costs of using medical assistants and clinical officers. However, the available information suggests a number of factors that influence the cost differences between doctors and their substitutes. These factors are summarized in Table 7.

Surgical-technician training in Mozambique was estimated to be "10 times cheaper" than training doctors [18]. The Kenya KMTC did not give specific cost data, but estimated that training of clinical officers was cheaper and further suggested that costs to the clients were lower. They estimated a basic clinical officer consultation fee (including some core medications) of about KSH 200 per client (about USD 2.50), whilst the minimum doctors charge for just the consultation was KSH 500. Clinical officers were also less likely to order lots of tests, which further reduced costs to clients.
Overbosch et al. (2002) estimates that antenatal care received from doctors in Ghana cost the client about 38\% more than if received from a nurse or a medical assistant [20]. Travel costs for the client are expected to be lower, as medical assistants based in rural centers are likely to be closer for clients than having to go to district hospitals. The Ghana DLSS showed that that $61.5 \%$ of people lived within $5 \mathrm{~km}$ of a nurse or medical assistant-run facility, compared to $33.5 \%$ for similar access to a doctor. Shutt (1994) estimated that $90 \%$ of Tanzanians lived within 5 $\mathrm{km}$ of a basic health facility, which reduces travel cost to clients. Caution is given about influence of skill levels and the effects of lack of drugs and equipment in such locations, which may still drive clients to go to hospitals [15].

\section{Conclusions}

The information from the review describes experiences with models of substitutions that have been used in African countries. The documentation and evaluation of these experiences have been very limited, but the general perception is that use of substitutes for doctors has had positive effects on health care and has sustained health services in rural and periurban deprived communities.

Substitutes with adequate additional training have been able to take up the important tasks of emergency care for life-threatening events in hard-to-reach areas. The advantages and disadvantages of using substitute health workers are summarized in Table 8.

With the very high demand for health workers in developed countries and the continuing economic crisis in African countries, substitute health workers will become essential resources in dealing with the increasing disease burden. Scaling up numbers produced and the scope of practice of substitutes and other mid-level health workers should be a priority consideration. For example, the need 
Table 8: Advantages and disadvantages of using substitute health workers (SHWs)

Possible advantages of SHWs

Possible disadvantages of using SHWs

I. Substitutes are country-specific, not internationally "tradable", and are more easily retained within the country

2. Emoluments and incentives for such cadres are significantly lower than for cadres substituted for

3. Pre-service training costs are also much lower

4. Academic entry requirements into technical training are less problematic and training is accessible to a wider range of entrants from all segments of society

5. All training is local and practical

6. Substitute cadres accept postings into rural/hardship areas and are retained there

7. Substitutes may reduce other service costs by requiring fewer diagnostic tests and less sophisticated equipment and by prescribing generic medications

8. They may relate better with communities by being less elitist and more integrated
I. Quality of care may suffer with poor clinical decision-making or poor supervision of their practice (they still require supervision by a professional)

2. Ethical considerations may be less strong in new cadres who don't have existing traditions and norms. Practice regulation is absent for many such cadres

3. The perceived low costs may be offset by poor treatment results and outcomes to patients and high morbidity

4. Scaling up the numbers of substitutes to achieve higher coverage will mean similar expansion in the numbers of professional cadres required for supportive supervision

5. Eventually cadres carrying out similar tasks want remuneration and incentives similar to those of the original cadres. Interprofessional conflict and demotivation may ensue to expand access to antiretroviral (ARV) treatment as envisaged by the World Health Organization's " 3 by 5 Initiative" will require significant increases in health worker numbers and skills, and this must be achieved quickly with a reduced training lag-time.

If substitute health workers are not properly regulated, supervised and motivated, there will be serious limitations to the roles they could play and to the quality of services they provide. It is evident that systematic monitoring and support are currently weak, but even then the results have been positive in terms of comparative outcomes to clients.

Recognition and formal appreciation of the roles of these health workers has been limited. Government incentives tend to target doctors, but often leave out these staff. Substitutes have been produced in limited numbers except in Tanzania and Kenya, which did not reflect the expectation that more of these cadres were needed.

In general, more investment is needed to expand training capacity and equip training institutions for these cadres, but from the evidence to date, it can be concluded that this would be a quite cost-effective strategy.

The discussion on using substitutes in Africa raised a number of issues that must be factored into the development of human resources policies and plans. Some of these are discussed below.

\section{Cadre proliferation}

There are concerns that unplanned substitution may stimulate a proliferation of cadres (Tanzania is an example with several types of middle- to lower-level staff types).
Creating new cadres must occur only after thorough strategic review and with an indication of their specific utility and roles. Substitutes were often considered as temporary measures to be phased out as more doctors were produced. A comprehensive rethink is needed in the face of the continuing health crisis; the African health sector must consider the possibility of establishing these cadres as a unique but integral and permanent part of health human resources. Mozambique appears to be a good example of a well-integrated use of substitute health workers.

\section{Inter-country recognition}

Health and HRH managers at a recent meeting of the East, Central and Southern African Health Community (July 2003), recommended that member countries should rationalize substitute cadres and paramedicals so as to agree upon common curricula and scopes of practice. The anticipated advantage is to enable shared training facilities and allow excess cadres to work in countries with inadequate numbers of appropriate workers. However, it should be recognized that a major attraction of substitutes is their country-specific nature, which permits them to be molded for a certain specific context and situation. Internationalization may lead to some of the same problems experienced with doctors and nurses, and it must be noted that significant brain drain also occurs between developing countries.

\section{Career systems and motivation}

The career structures of substitute health workers are not elaborate and progression is limited, with the exception of Tanzania, where assistant medical officers may continue into medical school. Under such restrictive circumstances, the possibility of underlying frustration and low motivation may be quite strong. As most of these qualifications 
are granted by ministry of health institutions and may not be accredited by universities, opportunities for further development training may be absent. Will allowing substitute health workers these opportunities deprive basic rural health services of providers?

A cautionary note is that data from Tawfik and Kinoti (2003) and USAID (2003) suggest that attrition due to HIV/AIDS among health workers may be higher with midlevel professionals, with deaths accounting for up to $40 \%$ of all attrition of nurses in Zambia and Malawi (clinical officers) $[21,22]$. Investments in substitute cadre development must aggressively assess and tackle this important waste of personnel.

\section{Recommendations}

The health crisis in Africa requires unprecedented mobilization of resources, and human resources for health must form an essential part of this mobilization. It would seem rational that substitute health workers be made a crucial component of strengthening HR capacity in sub-Saharan Africa. But the use of substitutes must involve comprehensive reviews and analysis of the concept and practice from experience gained so far. The paucity of hard evidence on substitutes limits the value of the experience so far gained.

- It is crucial to understand and appreciate the roles that substitute health workers are best suited for and how quality-of-care issues can best be dealt with. This is vital in confronting skepticism and battles for professional turf.

- Detailed studies are possibly ongoing in Mozambique; other countries will need similar studies. A regional meeting of experts on substitution (trainers, policy makers, clients, etc.) should reflect on the findings of evaluations and deliberate on feasible ways to scale up their use for the new challenges facing health systems, such as scaling of HIV/AIDS interventions and rolling back malaria, etc. Good evidence and effective analysis are needed to remove the skepticism and resistance of the traditional professions and other influential communities to effective use of substitutes.

- The issues of support and supervision of substitute care providers and indeed all health care workers is a problem that must be tackled. In-service and on-the-job training to reinforce good and effective practices are needed to develop a culture of ethics and leadership within the new professions, as well as to inculcate a culture of quality into the entire health care systems of African countries.

- Enhancing substitute health workers' roles should involve significant new investment in their training facilities. The case should be made through thorough investigation of the cost-effectiveness of using these cadres, including costs of poor practices and how these can best be avoided.

Use of substitute health workers is clearly an essential option for African countries. Even richer countries such as South Africa and Botswana are experiencing quite high health worker emigration, and many developed countries use a wide variety of medical assistants, nurse practitioners and nurse anesthetists. Special efforts are needed to build this component of the health workforce into the formidable force for good that it can easily become.

\section{Competing interests}

None declared.

\section{Acknowledgements}

This paper was derived from a desk review prepared for and funded by the World Health Organization's Department of Health Systems, now Department of Human Resources for Health. Despite the difficulties of communication across Africa and a general lack of published information on the subject, many people, including WHO Representatives and country health officials, were instrumental in assisting to find country documents and respond to questionnaires. The main respondents were from Kenya, Mozambique, Tanzania, Malawi, Zambia, Ghana and the Democratic Republic of the Congo.

\section{References}

I. Libombo A, Ustá MB: Mozambique abortion situation. Country report 200 I [http://www.ipasihcar.net/expacc/reports/MozambCR.html].

2. Akor SA, Adibo MEK, Azindow IM: Tracer Study of the Products of the Rural health Training School - Between 1989 and 1993. (MOH Preliminary Report). Accra 1995.

3. Sanders D, Dovlo D, Meeus W, Lehmann U: Public health in Africa. In Global Public Health: A New Era Edited by: Beaglehole R. Oxford: Oxford University Press; 2003:135-I55.

4. Bossert T, Beauvais J, Bowser D: Decentralization of Health Systems: Preliminary Review of Four Country Case Studies. Major Applied Research 6, Technical Report No. I Bethesda, MD: Partnerships for Health Reform Project, Abt Associates Inc; 2000.

5. Ngufor GF: Public service reforms and their impact on health sector personnel in Cameroon. In Public Service Reforms and Their Impact on Health Sector Personnel - Case Studies on Cameroon, Colombia, Jordan, Philippines, Poland, Uganda Geneva: International Labour Office; 1999.

6. Buchan J, Dal Poz MR: Skill mix in the health care workforce: Reviewing the evidence. Bulletin of the World Health Organization 2002, 80:575-580.

7. Mtonga $\mathrm{V}, \mathrm{Ndhlovu} \mathrm{M}$ : Midwives' role in management of elective abortion and post-abortion care. Zambian country report. Paper at the conference "Expanding Access; Advancing the Roles of Midlevel Providers in Menstrual Regulation and Elective Abortion Care" South Africa [http://www.ipasihcar.net/expacc/reports/ZRepF.PDF]. 2-6 December 2001

8. White SM, Thorpe RG, Maine D: Emergency obstetric surgery performed by nurses in Zaire. Lancet 1987, 2:612-613.

9. Vaz F, Bergstrom S, Vaz M, Langa J, Bugalho A: Training medical assistants for surgery. Policy and practice. Bulletin of the World Health Organization 1999, 77(8):688-69l.

10. Kidane G, Morrow R: Teaching mothers to provide home treatment of malaria in Tigray, Ethiopia: a randomized trial. Lancet 2000, 356:550-555.

II. United Republic of Tanzania, Ministry of Health. Department of Human Resource Development: Curriculum for Clinical Officers (Pre-service). Dar-Es-Salaam 200I.

12. Ministry of Health, Ghana: Rural Health Training School Curriculum - Medical Assistant. Kintampo 1996. 
13. Bergström S: Issue paper on maternal health care. SIDA Health Division Document 1998:I Stockholm: Swedish International Development Cooperation Agency (SIDA); 1998.

14. Lyttle D: The Malawi Orthopaedic Surgery Program. Section of Orthopedic Surgery [http://www.umanitoba.ca/faculties/medicine/units/surgeryl scalpel/spring [998/malawi.html]

15. Shutt L, Merrill M: Midterm Review Of The Tanzania Family Planning Services Support (FPSS) Project (62I-0I73). POPTECH Report No. 94-0II015. Washington, DC; prepared for US Agency for International Development. Edited and Produced by Population Technical Assistance Project 1994.

16. Ofori-Adjei D, Arhinful D: Effect of training on the clinical management of malaria by medical assistants in Ghana. Soc Sci Med 1996, 42(8): I I69-II76.

17. Lin Y, Franco LM: Assessing Malaria Treatment and Control at Peer Facilities in Malawi. Quality Assurance Project - Case Study Bethesda: US Agency for International Development (USAID) by the Quality Assurance Project (QAP); 2000.

18. Karolinska Institutet: Issues in Abortion Care 7: Deciding Women's Lives Are Worth Saving: Expanding the Role of Midlevel Providers in Safe Abortion Care Stockholm: IPAS IHCAR. December 2-6, 200 I

19. Picazo OF: Africa Region Human Development Working Paper Series: Better Health Outcomes from Limited Resources: Focusing on Priority Services in Malawi Washington, DC: The World Bank; 2002.

20. Overbosch GB, Nsowah-Nuamah NNN, Van Den Boom GJM, Damnyag L: Determinants of Antenatal Care Use in Ghana. Staff Working Paper WP-02 Amsterdam: Centre for World Food Studies. 13 November 2002

21. Tawfik L, Kinoti S: The Impact of HIVIAIDS on Health Systems and the Health Workforce in Sub-Saharan Africa Washington DC: SARA Project, USAID Bureau for Africa; 2003.

22. Support for Analysis and Research in Africa (SARA Project). HIVIAIDS and the Workforce Crisis in Health in Africa: Issues for Discussion Washington, DC: USAID Bureau for Africa; 2003.

Publish with Bio Med Central and every scientist can read your work free of charge

"BioMed Central will be the most significant development for disseminating the results of biomedical research in our lifetime. "

Sir Paul Nurse, Cancer Research UK

Your research papers will be:

- available free of charge to the entire biomedical community

- peer reviewed and published immediately upon acceptance

- cited in PubMed and archived on PubMed Central

- yours - you keep the copyright

Submit your manuscript here:

http://www.biomedcentral.com/info/publishing_adv.asp
BioMedcentral 